\title{
A prospective randomized study for comparison of onset time of intubation and intubating conditions using rocuronium with priming and without priming
}

\author{
Garg D. ${ }^{1}$, Mathur V. ${ }^{2}$, Meena R. ${ }^{3}$, Khare A. ${ }^{4}$, Sethi S.K. ${ }^{5}$, Thada B. ${ }^{6}$ \\ ${ }^{1}$ Dr Deepak Garg, Assistant Professor, ${ }^{2}$ Dr Veena Mathur, Professor, ${ }^{3}$ Dr Ramawtar Meena, PG Student, ${ }^{4}$ Dr Arvind \\ Khare, Associate Professor, ${ }^{5}$ Dr Surendra Kumar Sethi, Assistant Professor, ${ }^{6}$ Dr Beena Thada, Assistant Professor, All \\ authors are affiliated with Department of Anaesthesiology, JLN Medical College, Ajmer, Rajasthan, India.
}

Address for Correspondence: Dr Deepak Garg, Department of Anaesthesiology, JLN Medical College, Ajmer, Rajasthan, India. Email: drdeepakgarg04@gmail.com

\begin{abstract}
Background: Rocuronium, a non-depolarizing neuromuscular blocking agent, with priming, can be used as an alternative to succinylcholine for rapid sequence intubation because it produces rapid onset of intubation with comparable intubating conditions. We aimed to compare the onset time of intubation and intubating conditions using rocuronium with priming and without priming. Methods: Sixty adult patients of either sex, aged 18-60 years, ASA grade I and II, scheduled for various elective surgeries under general anaesthesia were randomly allocated into two groups (30 patients in each group). Group $\mathrm{P}$ received $0.06 \mathrm{mg} / \mathrm{kg}$ of rocuronium as priming dose and Group C received normal saline as placebo before induction. The patients in both groups received fentanyl $1.5 \mu \mathrm{g} / \mathrm{kg}$ and induced with propofol 2.5 $\mathrm{mg} / \mathrm{kg}$. The intubating dose of rocuronium $0.54 \mathrm{mg} / \mathrm{kg}$ for Group P and $0.6 \mathrm{mg} / \mathrm{kg}$ for Group C were given after $3 \mathrm{~min}$ of priming. The time interval between the intubating dose and the loss of T1 of TOF stimuli was considered as the onset time of intubation and Cooper's scoring system was used to compare the intubating conditions. Results: The onset time of intubation was significantly shorter $(\mathrm{P}<0.05)$ in group $\mathrm{P}(54.87 \pm 3.75 \mathrm{sec})$ than group $\mathrm{C}(94.37 \pm 3.52 \mathrm{sec})$. Intubating conditions were found to be excellent in both the groups with no any adverse effects. Conclusion: Rocuronium $(0.6 \mathrm{mg} / \mathrm{kg})$ with priming provides rapid onset time of intubation $(<60 \mathrm{sec})$ along with excellent intubating conditions without any adverse effects which may be particularly useful for rapid sequence intubation and where succinylcholine is contraindicated.
\end{abstract}

Keywords: Rocuronium, Priming, Intubating conditions, Endotracheal intubation, Neuromuscular blockade

\section{Introduction}

Succinylcholine has been the preferred depolarizing neuromuscular blocking agent for endotracheal intubation during general anaesthesia as it has rapid onset of action simultaneously providing excellent intubating conditions required to minimize the intubation associated trauma.

However, it is contraindicated in various conditions and associated with various side effects also including bradyarrhythmias, muscle fasciculations,

Manuscript received: $5^{\text {th }}$ May 2017

Reviewed: $15^{\text {th }}$ May 2017

Author Corrected: $24^{\text {th }}$ May 2017

Accepted for Publication: $31^{\text {st }}$ May 2017 hyperkalaemia, myalgia, masseter spasm, malignant hyperthermia with increased intracranial, intra-ocular, and intragastric pressures which are undesirable [1]. These side-effects and contraindications of succinylcholine have reduced its use and prompted the use of non-depolarizing neuromuscular blocking agents.

Rocuronium, a steroidal non-depolarizing neuromuscular blocking agent can be used as an alternative to succinylcholine for endotracheal intubation as it has rapid onset $(60-90 \mathrm{sec})$ of action among all nondepolarizing neuromuscular blocking agents and produces comparable intubating conditions to that of 
succinylcholine but has prolonged duration of action [13]. The only absolute contraindication to rocuronium is hyper-sensitivity reaction.

Various techniques have been used to further reduce the onset time of intubation along with providing adequate intubating conditions which may be particularly useful in rapid sequence intubation, including combination of muscle relaxants, timing principle, high dose nondepolarizing neuromuscular blocker, and priming principle. High doses of rocuronium may be associated with prolonged recovery time and timing principle requires perfect adjustment of induction times to prevent adverse effects and complications. Priming principle is one of the techniques which requires administration of a small dose (10\% of intubating dose) of non-depolarizing neuromuscular blocking agent followed by a large intubating dose after 2-4 min that produces a relatively rapid onset of neuromuscular blockade along with adequate intubating conditions for endotracheal intubation without undue prolongation of action or undesirable side effects. This technique is preferable in all patients who required rapid sequence intubation and in whom succinylcholine is contraindicated or undesirable [4-8]. In our study we have used rocuronium with intubating dose of 0.6 $\mathrm{mg} / \mathrm{kg}$ (i.e. $2 \mathrm{xED}_{95}$ ), priming dose of $0.06 \mathrm{mg} / \mathrm{kg}$ and priming interval of $3 \mathrm{~min}$.

We hypothesized that the onset time of neuromuscular blockade for intubation can be reduced by priming principle with rocuronium which is almost similar to the time required for succinylcholine $(<60 \mathrm{secs})$ at this particular dose and time interval. So this prospective randomized study was conducted to evaluate the effectiveness of the priming principle using rocuronium to reduce the onset time of intubation and to evaluate the intubating conditions.

\section{Methods}

Settings and Study design: This prospective randomized double blind placebo controlled study was conducted at our institute after obtaining approval from institutional ethical committee and written informed consent from all patients.

Inclusion criteria: Sixty patients of either sex, aged 18 to 60 years, American Society of Anesthesiologists (ASA) grade I and II, who were scheduled for various elective surgical procedures under general anaesthesia with tracheal intubation were included in our study.

Group Allocation and Randomization: They were randomly allocated into two groups of 30 each by computer generated random number table: Group P; Priming group, $(n=30)$ and Group C; Control group, $(n=30)$.

Exclusion criteria: Patients who had previous history of any allergic reaction to the study drug, neuromuscular disorders, psychiatric disorder, predicted difficult intubation, pregnant females, obese patients, patients on drugs having drug interactions with rocuronium and patients with kidney and liver diseases were excluded from our study.

Anaesthetic technique: All patients underwent a thorough pre-anaesthetic evaluation before surgery, with all relevant investigations. A written and informed consent was taken from all patients. All patients were kept NPO for 6 hours. After arrival in the operation theater, the $18 \mathrm{G}$ intravenous cannula was secured and balance salt solution was started. All baseline vital parameters were recorded including heart rate (HR), non invasive blood pressure (NIBP), electrocardiogram (ECG), pulse oximeter $\left(\mathrm{SpO}_{2}\right)$. The skin above the wrist was prepared by shaving if required and cleaning with spirit. After explaining the patient about the neuromuscular monitoring and the nerve stimulation technique, nerve stimulator surface electrodes were applied over the ulnar nerve course above the wrist to the contralateral upper limb, observation done on thumb and supramaximal stimulus was automatically detected by module (Infinity® Trident ${ }^{\circledR}$ NMT SmartPod $\left.{ }^{\circledR}\right)$. The intubating dose of rocuronium $(0.6 \mathrm{mg} / \mathrm{kg})$ was diluted to $5 \mathrm{ml}$ with normal saline. In Group P, priming dose $(0.06 \mathrm{mg} / \mathrm{kg})$ of rocuronium was taken from the total intubating dose $(0.6$ $\mathrm{mg} / \mathrm{kg}$ ) and diluted to $2 \mathrm{ml}$ with normal saline and the remaining intubating dose was again diluted to $5 \mathrm{ml}$ with normal saline. Similarly in Group C, $2 \mathrm{ml}$ of normal saline was taken in a $5 \mathrm{ml}$ syringe. To maintain the double blinding, all the drugs were loaded, labeled and administered by another anaesthesiologist who did not participate in our study while the anaesthesiologist who intubated the patients and observed the results was also blinded to the study and diluted drugs. After pre-oxygenation with $100 \%$ oxygen for $3 \mathrm{~min}$, the priming dose of rocuronium or normal saline was given to the patients of Group P and C respectively and the patients were observed and asked about any side effects associated with 
priming like the drooping of upper eyelid, double vision, difficulty in breathing and difficulty in swallowing. After 1.5 min of giving priming dose, fentanyl $(1.5 \mu \mathrm{g} / \mathrm{kg})$ was given intravenously in both groups. After 2.5 min of the priming dose, patients were induced with propofol $(2.5 \mathrm{mg} / \mathrm{kg})$ given intravenously followed by intubating dose of rocuronium injected after $3 \mathrm{~min}$ of the priming or normal saline injection. After giving the intubating dose of rocuronium, the supramaximally set train of four (TOF) stimulation of frequency $2 \mathrm{~Hz}$ was applied over the ulnar nerve above the wrist through surface electrodes, was repeated every 10 seconds and observed visually for disappearance of adduction of thumb and loss of $\mathrm{T}_{1}$ of TOF stimuli. The loss of $\mathrm{T}_{1}$ of TOF stimuli was considered adequate neuromuscular blockade for intubation, The time interval between the intubating dose and the loss of $\mathrm{T}_{1}$ of TOF stimuli was considered as the onset time of intubation, after that endotracheal intubation was done by blinded anaesthesiologist and intubating conditions were assessed and graded by using Cooper scoring system [11]. The maximum total score is 9 as the highest score is 3 with each parameter included Jaw relaxation, Vocal cords and Response to intubation. Intubating conditions were graded as excellent (score 8-9), good (6-7), fair (3-5), and poor (0-2). (Table 1).

Table-1: Cooper scoring system.

\begin{tabular}{|c|c|c|c|}
\hline Score & Jaw relaxation & Vocal cords & Response to intubation \\
\hline 0 & Impossible to open & Closed (adducted) & Severe coughing or bucking \\
\hline 1 & Opens with difficulty & Closing & Mild coughing \\
\hline 2 & Moderate opening & Moving & Slight diaphragmatic movement \\
\hline 3 & Easy opening & Open (relaxed) & No movement \\
\hline
\end{tabular}

Observed parameters: The various haemodynamic parameters including $\mathrm{HR}, \mathrm{SBP}, \mathrm{DBP}, \mathrm{MAP}, \mathrm{SpO}_{2}$ were observed at baseline, after priming, after induction, 1 min and 5 min after endotracheal intubation and any adverse effects of priming were also observed. Intraoperativaly, anaesthesia was maintained by using isoflurane, $60 \% \mathrm{~N}_{2} \mathrm{O}$ and $40 \% \mathrm{O}_{2}$ in both the groups.

Statistical analysis: The sample size was calculated to be 30 patients in each group and was based on previous studies. The parameters and patient data were recorded and entered in Microsoft Excel sheet (Microsoft Office 2007 Professional) and Statistical package for social sciences (SPSS) for Windows version 10.0 software, Chicago, SPSS Inc. was used for statistical analysis. The continuous variables such as age, weight and onset time of intubation were expressed as mean and standard deviation while the hypothesis testing was performed with the unpaired t-test. Categorical data were presented as number or percentage and compared using the Chi-square test. $\mathrm{P}<0.05$ was considered as statistically significant.

\section{Results}

The patients in both the groups were comparable with respect to patient's characteristics including age, weight, sex, ASA grade distribution. ( $\mathrm{P}>0.05)$, (Table 2).

The onset time of intubation was significantly lower in group $\mathrm{P}(54.87 \pm 3.75 \mathrm{sec})$ than group $\mathrm{C}(94.37 \pm 3.52 \mathrm{sec})$, ( $\mathrm{P}<$ 0.01), (Figure 1).The intubating conditions were assessed and graded using Cooper's scoring system and were found to be excellent (score 8-9) in both the groups (Figure 2).

The baseline MAP and HR were comparable in both groups ( $\mathrm{P}>0.05)$. A slight increase in MAP and HR was noted just after priming which reduced after induction and again raised after intubation. However changes were clinically acceptable at all times and were statistically insignificant when compared between two groups $(\mathrm{P}>0.05)$. (fig 3, 4)

In our study adverse effects of priming like diplopia, dysphagia, blurred vision etc. were not observed in any patient in both the groups. 
Table-2: Demographic data of patients in both groups.

\begin{tabular}{|c|c|c|c|}
\hline Parameters & $\begin{array}{c}\text { Group P } \\
(\mathbf{n = 3 0})\end{array}$ & $\begin{array}{c}\text { Group C } \\
(\mathbf{n}=\mathbf{3 0})\end{array}$ & 0.7351 \\
\hline Age (years) & $41.93 \pm 9.57$ & $41.03 \pm 10.89$ & 0.7543 \\
Weight (kg) & $62.23 \pm 9.78$ & $63.00 \pm 9.09$ & 0.80 \\
Sex (Male/Female) & $13 / 17$ & $14 / 16$ & 0.7892 \\
\hline ASA Grade I/ II & $18 / 12$ & $20 / 10$ & \\
\hline
\end{tabular}

Data are represented as Mean \pm SD or number.

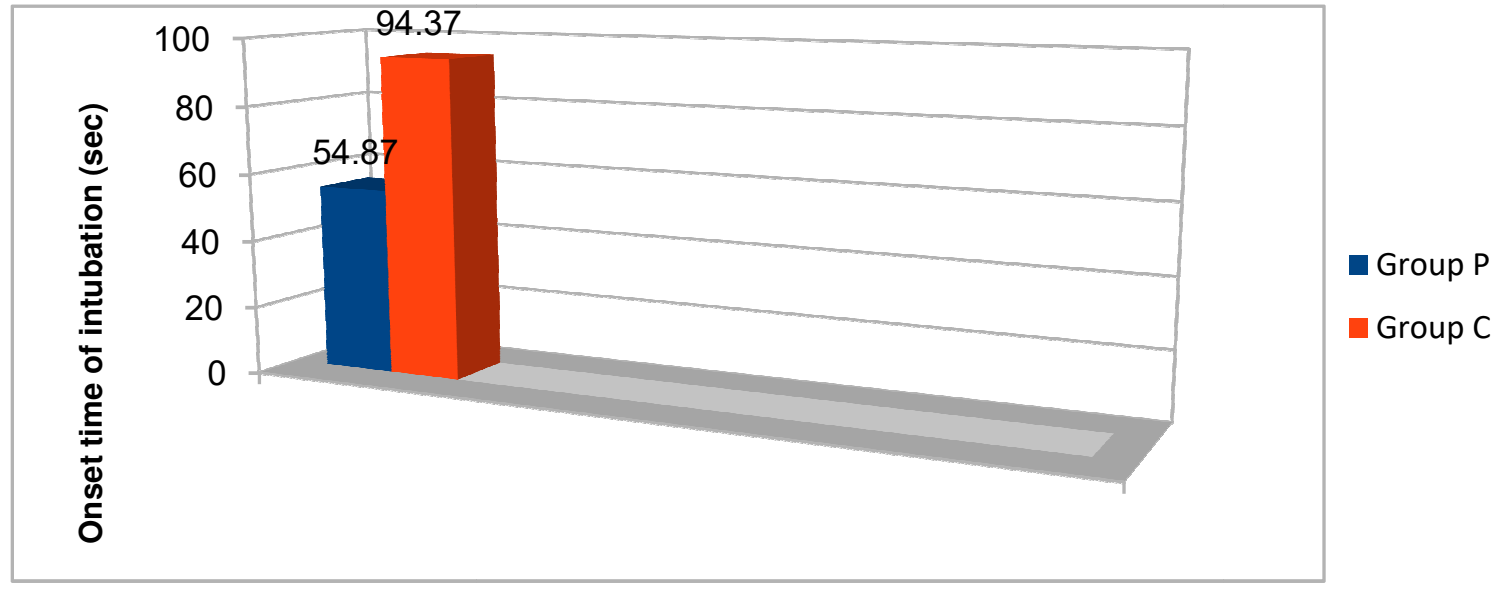

Figure-1: Comparison of mean onset time of intubation between two groups

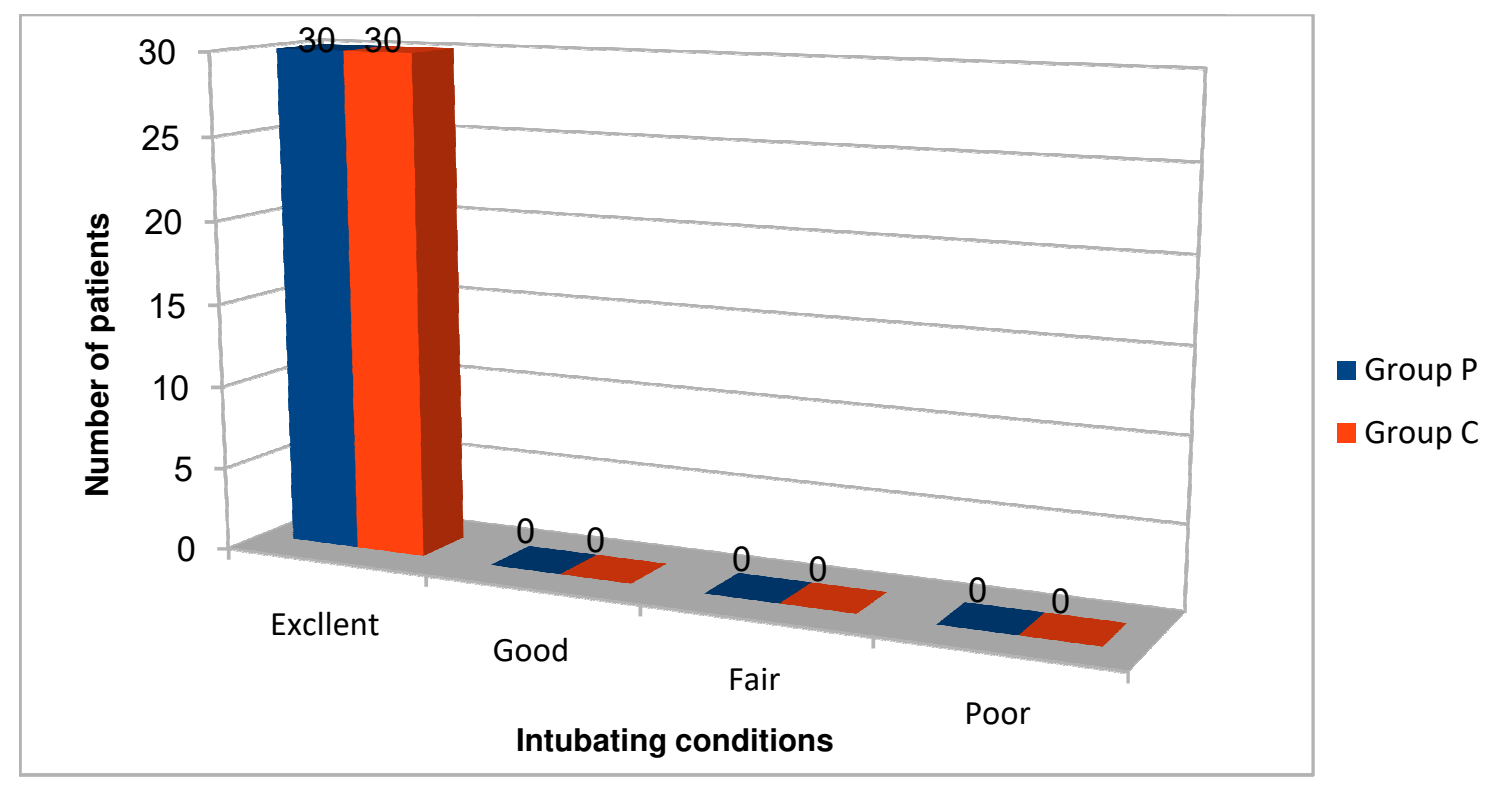

Figure-2: Comparison of intubating conditions in both groups 


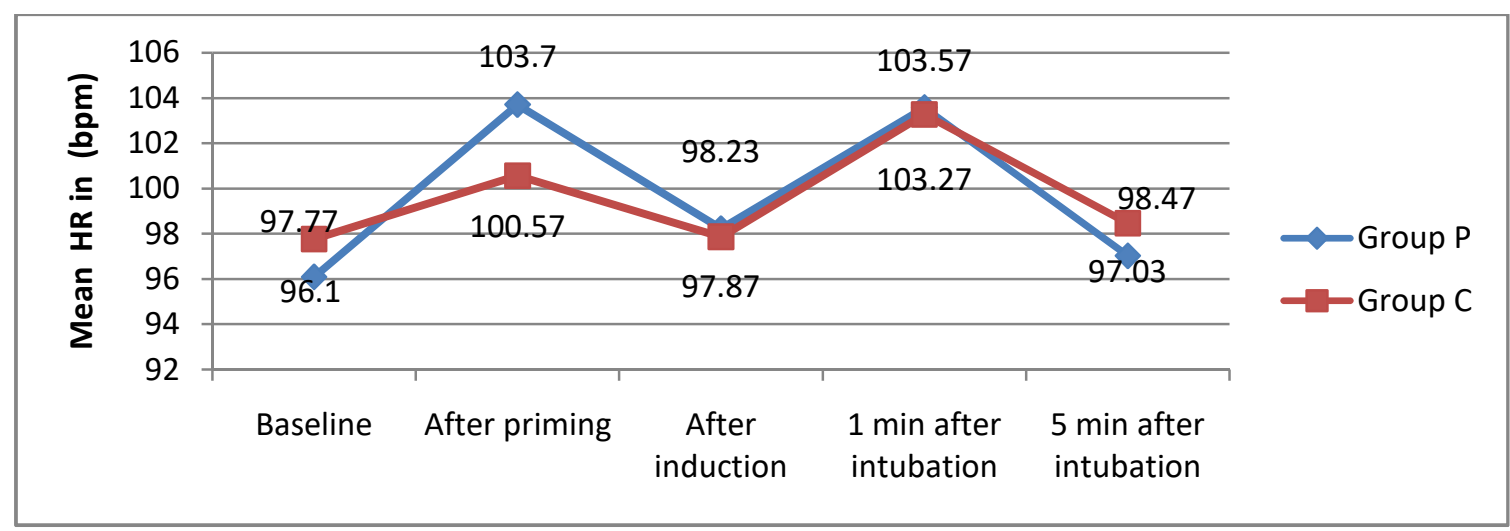

Figure-3: Comparison of mean heart rate (HR) in both groups

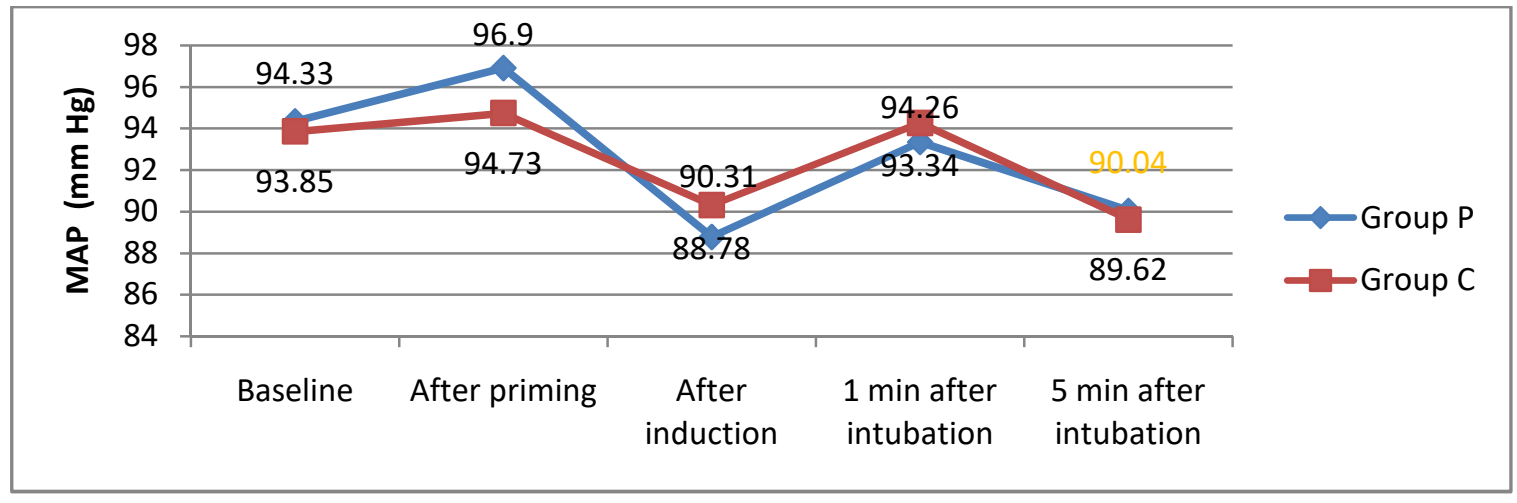

Figure-4: Comparison of mean arterial pressure (MAP) in both groups

\section{Discussion}

Non-depolarizing neuromuscular blocking agents like rocuronium with priming could be an alternative to succinylcholine for rapid sequence intubation without predicted difficult intubation situations and in conditions where succinylcholine is contraindicated. The onset of action of a non-depolarizing neuromuscular blocking agent can be reduced with the use of small priming dose of neuromuscular blocking agent before the intubating dose which provides rapid and excellent intubating conditions without undesirable side effects [8]. The primary objective of our study was to compare the onset time of intubation and intubating conditions using rocuronium with priming and without priming.

The use of $3 \mathrm{~min}$ priming interval in our study is supported by study done by Yavascaoglu et al [10], in which they found that the priming interval of $3 \mathrm{~min}$ provided both the faster onset time and better intubating conditions in rocuronium as compared with 2 min interval and similar results have also been obtained by Sridhar et al [12], at this particular time interval for priming.
In our study we found that the onset time of intubation was $54.87 \pm 3.75 \mathrm{sec}$ in the priming group and $94.37 \pm$ $3.52 \mathrm{sec}$ in the control group, the onset time in group $\mathrm{P}$ was significantly shorter, $(\mathrm{P}<0.05)$. Intubating conditions were assessed by using Cooper's scoring system and all patients exhibited excellent intubating conditions (score 8-9) in both groups.

The results obtained in our study are similar to those obtained in study conducted by Rao M H et al [9]. They found that the onset time of intubation was significantly shorter in the priming group $(50.6 \pm 7.4 \mathrm{~s})$ than the control group $(94.0 \pm 11.62 \mathrm{~s})$ with excellent intubating conditions in both the groups. Naguib et al also have shown a more rapid onset time of intubation and intubatiing conditions comparable to the block of succinylcholine, with the use of priming technique[13]. Griffith et al also in their study observed significantly shorter onset time of intubation in the priming group however they had used single twitch method for assessment of adequate neuromuscular blockade for intubation whereas we used the train of four (TOF) method for its assessment [14]. 
The reduction in onset time of intubation with excellent intubating conditions using rocuronium with priming could be explained by different mechanisms. Firstly, the small priming dose of a non-depolarizing neuromuscular blocking agent occupies a critical proportion of post synaptic nicotinic receptors at neuromuscular junction before clinically appreciable reduction in neuromuscular transmission and the large intubating dose then blocks more rapidly the remaining receptors necessary for clinical paralysis required for rapid onset of intubation. The size of the priming dose and the time interval between priming and intubating dose are of fundamental importance in this principle in order to occupy the critical proportion of receptors and to maximize receptor occupancy and profound blockade. According to second theory, the priming dose blocks presynaptic nicotinic receptors, reducing the mobilization and release of acetylcholine to such extent that the intubating dose produces more rapid and profound neuromuscular blockade $[4,6,10]$.

The concomitant use of propofol along with moderate doses of opioid like fentanyl during induction may have improved the intubating conditions through their synergistic mechanism as reported by Crul et al [15]. Ortiz et al found that duration of neuromuscular block was not prolonged after priming and responses to rocuronium doses during surgery when needed were normal. However, rocuronium itself may pose potential problem in difficult airway situations because of its prolonged duration of action [16].

In our study no significant haemodynamic changes (HR, MAP) were seen between two groups $(\mathrm{P}>0.05)$ at baseline, after priming, after induction, $1 \mathrm{~min}$ and $5 \mathrm{~min}$ after intubation. We found that there was slight increase in heart rate and mean arterial blood pressure just after the priming dose which may be attributed to rocuronium induced pain on injection or it's vagolytic action. The slight decrease in both heart rate and blood pressure noted after induction may be due to vagotonic action of fentanyl and the induction dose of propofol but these changes were not significant. The slight increase in HR and MAP 1 min post intubation may be attributed to stress response to laryngoscopy and intubation $(\mathrm{P}>0.05)$, but were in clinically acceptable range which may be due to use of propofol, fentanyl and excellent intubating conditions obtained in both the groups. Rao $\mathrm{MH}$ et al found no significant changes in heart rate and blood pressure following rocuronium administration. They observed a slight increase in HR and MAP 1 min post intubation,but that was not significant [9]. This may be due to stress response to laryngoscopy and intubation similar to our study. Shorten et al compared rocuronium $0.9 \mathrm{mg} / \mathrm{kg}$ with vecuronium $0.12 \mathrm{mg} / \mathrm{kg}$ in elderly patients and found no significant change in heart rate, arterial blood pressure or plasma epinephrine concentrations in both the groups, which also concurs with our study [17].

None of the patients in our study had experienced adverse effects of priming. The symptoms related to adverse effects of priming could not have been observed in our study due to the use of fentanyl as premedication after priming which might have a role in suppression of these adverse effects. However, as noted by Aziz et al in their study, priming technique should be used carefully as it may not be safe in elderly patients due to risk of greater decreases in oxygen saturation and pulmonary function [18].

\section{Conclusion}

We conclude that the onset time of intubation after priming with $10 \%(0.06 \mathrm{mg} / \mathrm{kg})$ of intubating dose $(0.6$ $\mathrm{mg} / \mathrm{kg}$ ) of rocuronium and a priming interval of $3 \mathrm{~min}$ was significantly lower $(<60$ secs $)$ than the control group without priming, along with excellent intubating conditions and without any side effect of precurarization, which may be helpful in rapid sequence intubation without predicted difficult intubation situations.

\section{Funding: Nil, Conflict of interest: None Permission of IRB: Yes}

\section{References}

1. Savarese JJ, Caldwell JE, Lien CA, Miller RD. Pharmacology of muscle relaxants and their antagonists. In: Miller, (Editor), 6th ed. Philadelphia Churchill Livingstone; 2004;1:490.

2. Magorian T, Flannery KB, Miller RD. Comparison of rocuronium, succinylcholine, and vecuronium for rapidsequence induction of anesthesia in adult patients. Anesthesiology. 1993 Nov;79(5):913-8.

3. Lowry DW, Mirakhur RK, McCarthy GJ, Carroll MT, McCourt KC. Neuromuscular effects of rocuronium during sevoflurane, isoflurane, and intravenous anesthesia. Anesth Analg. 1998 Oct; 87 (4): 936-40. 
4. Shashank DS, Singh NR, Singh LK. Effects of pretreatment with different neuromuscular blocking agents on facilitation of intubation with rocuronium: A prospective randomized comparative study. Indian $\mathrm{J}$ Anaesth 2014;58(3):303-8. DOI: 10.4103/0019-5049. 135043

5. Mishra LD, Nath SS, Bhattacharya DP. Effect of priming on intubating conditions produced by atracurium. Indian J Anaesth 2003;47(6):458-62.

6. Kopman AF, Khan NA, Neuman GG. Precurarization and priming: a theoretical analysis of safety and timing. Anesth Analg. 2001 Nov;93(5):1253-6.

7. Bissinger U, Rex C, Lenz G. [Intubation conditions following administration of atracurium and vecuronium. Bolus method versus priming technique]. Anaesthesist. 1996 Jun;45(6):512-7.

8. Jones RM. The priming principle: how does it work and should we be using it? Br J Anaesth. 1989 Jul;63 (1):1-3.

9. Rao MH, Venkatraman A, Malleswari R. Comparison of intubating conditions between rocuronium with priming and without priming: Randomized and double-blind study. Indian J Anaesth 2011; 55(5):494-8. DOI: 10.4103/0019-5049.89882

10. Yavascaoglu B, Cebelli V, Kelebek N, Uckunkaya $\mathrm{N}$, Kutlay O.Comparison of different priming techniques on the onset time and intubating conditions of rocuronium. Eur J Anaesthesiol 2002 Jul;19(7): 517-21.

11. Cooper R, Mirakhur RK, Clarke RS, Boules Z. Comparison of intubating conditions after administration of Org 9246 (rocuronium) and suxamethonium. Br J Anaesth. 1992 Sep;69(3):269-73.

12. Sridhar SK, Lagoo JY, Sathyanarayana PS. A comparative study to evaluate the effects of priming on intubating time and conditions with rocuronium bromide. Karnataka Anaesth J 2015;1(2):55-9. DOI:10. 4103/2394-6954.163077

13. Naguib M. Different priming techniques, including mivacurium, accelerate the onset of rocuronium. Can $\mathbf{J}$ Anesth 1994;41(10):902-7. doi:10.1007/BF03010932.

14. Griffith KE, Joshi GP, Whitman PF, Garg SA. Priming with rocuronium accelerates the onset of neuromuscular blockade. J Clin Anesth. 1997 May;9 (3):204-7.

15. Crul JF, Vanbelleghem V, Buyse L, Heylen R, van Egmond J. Rocuronium with alfentanil and propofol allows intubation within 45 seconds. Eur J Anaesthesiol Suppl. 1995 Sep;11:111-2.

16. J. R. Ortiz-Gómez, F. Carrascosa, J. J. PérezCajaraville. Comparative study of intubating conditions at the first minute with suxamethonium, rocuronium and different priming techniques of rocuronium. Eur $\mathbf{J}$ Anaesthesiol 2005; 22: 263-268

17. Shorten GD, Uppington J, Comunale ME. Changes in plasma catecholamine concentrations and haemodynamic effects of rocuronium and vecuronium in elderly patients.Eur J Anaesthesiol 1998 May;15(3) : 335-41.

18. Aziz L, Jahangir SM, Choudhury SN, Rahman K, Ohta Y, Hirakawa M. The effect of priming with vecuronium and rocuronium on young and elderly patients. Anesth Analg. 1997 Sep;85(3):663-6.

\section{How to cite this article?}

Garg D, Mathur V, Meena R, Khare A, Sethi S.K, Thada B. A prospective randomized study for comparison of onset time of intubation and intubating conditions using rocuronium with priming and without priming. Int J Med Res Rev 2017;5(05):531-537. doi:10.17511/ijmrr. 2017.i05.15. 